$25 \mathrm{cc}$. portions into the four jars of dilute hydrochloric acid in the order, water, acetic acid, chloracetic acid, and sulphuric acid.

Observations. - The jars to which the water solution and the acetic acid solution are added show a very slight and nearly equal turbidity. The turbidity is much greater in the case of the chloracetic acid, and again much greater in the case of the sulphuric acid.

\title{
ON THE PREPARATION OF TRIPHENYLCHLORMETHANE.
}

By M. GOMBERG.

Received October 4, 1900 .

$\mathrm{T}$ is generally stated in smaller as well as in larger ${ }^{1}$ text-books

on organic chemistry, that when carbon tetrachloride is treated with benzene and aluminum chloride triphenylchlormethane is the principal product of the reaction. This statement is entirely erroneous.

Friedel and Crafts, who were the first to study this reaction, reported ${ }^{2}$ that they obtained in this way tetraphenylmethane. $E$. and $O$. Fischer ${ }^{3}$ were unable to verify this result, but could obtain only triphenylmethane. It is to be presumed that they carried on this reaction in a manner analogous to that followed in the preparation of triphenylmethane from chloroform, $i . e$, the resulting products, after being freed from the chloride of aluminum and the excess of benzene, were subjected to fractional distillation at the high temperature of $200^{\circ}-360^{\circ} \mathrm{C}$. Later, Friedel and $\mathrm{Crafts}^{4}$ found that the results vary according to the manner of procedure. On distilling the crude products at a high temperature they also obtained triphenylmethane and thus confirmed $E_{\text {. }}$ and $O$. Fischer's results. But if the entire mixture as obtained by the action of aluminum chloride and benzene upon carbon tetrachloride is at once treated with water, it furnishes large quantities of triphenylcarbinol. From this they concluded that the reaction results principally in the formation of triphenylchlormethane, $\left(\mathrm{C}_{6} \mathrm{H}_{5}\right)_{3} \mathrm{C} . \mathrm{Cl}$, and this on treatment with water furnishes the corresponding carbinol. They confirmed this

1 Beilstein: Handbuch, II, 287 (3rd edition).

2 Compt. rend., $1453(1877)$.

3 Ann. Chem. (Liebig), 194, 254.

4 Ann.chim. phys., I, 497 (1884). 
conclusion by the conversion of the crude chloride into the ethoxy compound :

$$
\left(\mathrm{C}_{6} \mathrm{H}_{5}\right)_{3} \mathrm{C} \cdot \mathrm{Cl}+\mathrm{HOC}_{2} \mathrm{H}_{5}=\left(\mathrm{C}_{6} \mathrm{H}_{5}\right)_{3} \mathrm{C} \cdot \mathrm{OC}_{2} \mathrm{H}_{5}+\mathrm{HCl} \text {. }
$$

Triphenylmethane is therefore not the first product of the action of benzene upon carbon tetrachloride, but is one of the decomposition products of triphenylchlormethane, formed when the latter is subjected to high heat. That this is likely to occur had been previously shown by $\mathrm{E}$. and $\mathrm{O}$. Fischer on the pure chlorocompound. ${ }^{1}$

Of others who have employed Friedel and Crafts' reaction upon carbon tetrachloride itself or upon its phenylated derivatives may be mentioned Doebner and Magati, ${ }^{2}$ Schwartz, ${ }^{3}$ Weisse, ${ }^{4}$ and V. Meyer. ${ }^{5}$ They all report the formation of triphenylmethane,due, no doubt, in every instance to the subsequent decomposition of the triphenylchlormethane. In this connection, Nencki and Meissel's work may be mentioned. Nencki $i^{6}$ has shown that ferric chloride may with advantage be substituted for aluminum chloride in many syntheses where Friedel and Crafts' reaction is used. According to Meissel, ' by the use of this reagent upon a mixture of benzene and carbon tetrachloride, triphenylchlormethane is formed, as by subsequent treatment 75 per cent. of the theoretical amount of triphenylcarbinol can be obtained. "No triphenylmethane is formed in this reaction as is the case when aluminum chloride is employed."

As a matter of fact, however, the action of aluminum chloride upon a mixture of carbon tetrachloride and benzene is exceedingly smooth, provided certain conditions are observed. I have used this reaction many times, and not in a single instance could I detect any trace of triphenylmethane. Friedel and Crafts are entirely correct that triphenylchlormethane is the principal product of the reaction. By observing certain precautions as to temperature of heating and manner of decomposing the chloride of aluminum, the triphenylchlormethane itself can be easily isolated and obtained very pure, with a yield from $70-90$ per cent. of the

\footnotetext{
1 Ann. Chem. (Liebig), 194, 257.

2 Ibid., 12, 1468.

8 Ibid., 14, 1523.

4 Ibid, 28,$1537 ; 29,1402$.

5 Ibid., 28, 2792.

(Ibid., 30, 1776; 32, 2415.

I Ibid., 32, 2422.
} 
theoretical quantity. This forms by far the best method for the preparation of this compound, as by means of it one can easily obtain 500 grams of the pure triphenylchlormethane in less than two days. The chloro compound may, therefore, with advantage replace the triphenylbrommethane in many reactions, as the latter is usually made from the rather expensive triphenylmethane. Even by the method of Allen and Kölliker ${ }^{1}$ it cannot always be obtained free from the bromanthracenes.

EXPERIMENTAL, PAR'T.

Aluminum Chloride.-Gattermann ${ }^{2}$ called attention to the fact that the yield and smoothness of Friedel and Crafts' reaction depend in a great measure upon the purity of the aluminum chloride. He prepared the latter by the action of hydrochloric acid gas upon heated aluminum. This is at present the method generally employed. Biltz" has noticed that in some instances pure, freshly prepared aluninum chloride is rather a detriment, and old, slightly deteriorated reagent is to be preferred. That chlorine acts upon metallic aluninum is a fact well known, but has seldom been employed in laboratories for the preparation of the chloride. ${ }^{*}$ I find this to be by far the most convenient method of preparing aluminum chloride, especially when one has access to liquid chlorine. The reagent obtained in this manner is very reactive. About 50 grans of aluminum turnings, thoroughly washed and dried, are placed in a combustion tube, the metal being held in place by loose plugs of asbestos wool. The tube is placed in a combustion furnace, one end is connected with the chlorine tank, and the other fits by means of an asbestos stopper into an iron receiver. "The portion of the tube nearest to the receiver is now heated, and a rapid stream of dry chlorine is passed into the tube. The gas attacks at once the cold portion of the metal, provided the stream of chlorine is quite rapid. The heat of the reaction is very great, and the metal is kept glowing throughout the length of about 3 inches. In about one and one-fourth to one and one-half hours the reac-

I Ann. Chem. (Liebig), 227, ㄴo.

2 Stockhatusen u. Gattermaun: Ber, d. chem. Ges., 25, 3521.

Ibid., 26, I960.

$4 \mathrm{My}$ attention is called to the fact that Erdmann recommends this reaction in his "Introduction to Organic Preparations," p. 43.

5 Gattermaun: "Praxis des organischen Chemikers," III. Auflage. 
tion is finished. The yield is usually $190-200$ grams of aluminum chloride, which represents about 80 per cent. of the theory. Sometimes even 90 per cent. can be obtained. By this method $700-800$ grams of the chloride can be prepared in one day by using only one furnace. The reagent prepared in this way is very reactive, and retains this property apparently unimpaired even after being kept for two months.

Triphenylchlormethane, $\left(\mathrm{C}_{6} \mathrm{H}_{5}\right)_{3} \mathrm{C} . \mathrm{Cl}$. The proportions which were found to give good results are I part of carbon tetrachloride, 3.5 parts of benzene, and about 1.25 parts of aluminum chloride. The carbon tetrachloride and benzene were thoroughly dried over calcium chloride and carefully fractionated. The two liquids are placed in a round-bottomed flask connected with a long inverted condenser by an arrangement as suggested by Anschïz.' The aluminum chloride is added in portions of about 20 grams each. The reaction becomes very violent. I have not attempted to moderate it by cooling. After all the chloride is added, the mixture is heated on the water-bath for about an hour. The next step, the decomposition of the aluminum chloride, requires certain precautions. The cooled mixture is poured in a slow stream upon a good quantity of pounded ice, the jar containiug the latter being itself surrounded with a cooling mixture. The addition of the reaction product to the ice should be done slowly, and with constant stirring. Benzene is also added from time to time in order to keep the triphenylchlormethane in solution. After all has been added the benzene solution is separated from the ice and water by a separating funnel, shaken once with ice-water containing hydrochloric acid, and once with ice-water alone. It is advisable to leave the two solutions in contact with each other as short a time as possible. The filtered benzene solution is dried thoroughly over calcium chloride, and concentrated on the water-bath as far as possible. On cooling, over half of the pure triphenylchlormethane separates in large crystals. These are removed by filtration and washed once or twice with dry ether, in which the chloro compound is not very soluble. The filtrate is distilled first on a water-bath at ordinary pressure, and then concentrated by distilling off the benzene under diminished pressure. To the very concentrated solution dry ether is again

1 Ann. Chem. (Liebig), $235,1_{54}$. 
added, and another large portion of the chloro compound is precipitated. This is treated in the same way as the first crop of crystals, and is just as pure, retaining a slight pink color. The mother liquid is subjected once more to the same treatmentevaporating the ether, and concentrating under diminished pressure-and yields a third crop of crystals. By this treatment the triphenylchlormethane is freed from both the coloring-matter and the triphenylcarbinol, since both of these are quite soluble in ether. The last mother-liquid contains all the coloring-matter. In several instances I have evaporated it to a thick sirup, dried on a porous plate, boiled with water, and obtained considerable quantities of triphenylcarbinol,--but never any indication of triphenylmethane. The yield of the pure chloro compound varies from $70-85$ per cent. and enough carbinol can be obtained to account for a yield of $90-95$ per cent. of the theory.

In the following table are given some of the results obtained:

\begin{tabular}{|c|c|c|c|c|c|}
\hline $\begin{array}{c}\text { Carbon tetra- } \\
\text { chloride. } \\
\text { Grams. }\end{array}$ & $\begin{array}{c}\text { Benzene. } \\
\text { Grams. }\end{array}$ & $\begin{array}{l}\text { Aluminum } \\
\text { chloride. } \\
\text { Grams. }\end{array}$ & $\begin{array}{l}\text { rriphenyl- } \\
\text { chlor- } \\
\text { methane. } \\
\text { Grams. }\end{array}$ & $\begin{array}{l}\text { Per } \\
\text { cent. of } \\
\text { theory. }\end{array}$ & $\begin{array}{l}\text { Tripheny1- } \\
\text { carbinol. } \\
\text { Grams. }\end{array}$ \\
\hline$I \ldots \ldots \ldots \ldots 300$ & 1000 & 300 & 390 & 72 & 22 \\
\hline II $\ldots \ldots \ldots \ldots 360$ & I500 & 410 & 500 & 71 & .. \\
\hline III $\ldots \ldots \ldots \ldots \quad 39$ & I 50 & 50 & $5 \mathrm{I}$ & 78 & Io \\
\hline IV $\ldots \ldots \ldots \cdots$ I 29 & 500 & I5o & $20 \mathrm{I}$ & 87 & . \\
\hline
\end{tabular}

It has already been mentioned that the triphenylchlormethane obtained by this reaction is quite pure, and can be employed for most reactions without further purification. It melts usually at $108^{\circ}-112^{\circ} \mathrm{C}$, while Hemilian ${ }^{1}$ gives it as $105^{\circ}-115^{\circ} . \mathrm{C}$

The following method was found to give equally good results as Carius' for the estimation of chlorine in this substance. The chloro compound is dissolved in alcoholic potash ( 2 per cent.) and heated for a short time on the water-bath. The alcohol is evaporated, the residue dissolved in water, filtered from the ethyl ether of triphenylcarbinol, and the chlorine is estimated in the filtrate in the usual manner with silver nitrate.

In the following table are given the results of analysis of $I$, III, IV of the preceding table. The chloro compound had been obtained in three separate crops. Each crop was analyzed by itself.

1 Ber. d. chem. Ges., 7, 1203. 


\begin{tabular}{|c|c|c|c|c|}
\hline & $\begin{array}{l}\text { First } \\
\text { crop. }\end{array}$ & $\begin{array}{l}\text { Second } \\
\text { crop. }\end{array}$ & $\begin{array}{l}\text { Third } \\
\text { crop. }\end{array}$ & $\begin{array}{l}\text { Calculated for } \\
\left(\mathrm{C}_{6} \mathrm{H}_{5}\right)_{3} \mathrm{C} . \mathrm{Cl}\end{array}$ \\
\hline$I \ldots \ldots \ldots \ldots \ldots$ & 12.35 & 12.74 & 12.69 & 12.75 \\
\hline III $\ldots \ldots \ldots \ldots \ldots$ & 12.45 & 12.48 & 12.49 & $\mathrm{I} 2.75$ \\
\hline IV $\ldots \ldots \ldots \ldots \ldots \ldots$ & 12.62 & 12.60 & I2.56 & 12.75 \\
\hline
\end{tabular}

The product obtained by this method may, therefore, be considered quite pure. For further purification it can be recrystallized from benzene alone, or better by precipitating it from a concentrated solution in benzene by means of dry ether. By this method large quantities of pure triphenylchlormethane can be more easily obtained than by the old method, ${ }^{1}$ - by treating triphenylcarbinol with phosphorus pentachloride.

In conclusion I wish to express my thanks to Messrs. A. G. Marion, H. W. Emerson, and F. L. Woods for their kind assistance in carrying out some of the experimental work.

UNIVERSITY OF MICHIGAN,

CHEMICAL I,ABORATORY.

\title{
AN INSTANCE OF TRIVALENT CARBON: TRIPHENYL- METHYL.
}

\author{
BY M. GOMBERG. \\ Received October 4, 1900.
}

[PRELIMINARY PAPER.]

SOME time ago ${ }^{2}$ I published a method of preparing tetra$\checkmark$ phenylmethane. The yield was rather small and I was obliged to study the solubilities, composition, molecular weight, and the nitro derivative on about 0.5 gram of the hydrocarbon. The stereochemical interest attached to this compound has induced me to take up the subject once more, in the hope of obtaining larger yields. I have, therefore, gone over most of the methods which have been tried by others for the preparation of tetraphenylmethane. My results, while differing in detail from those published by others, agree in the main, 一the hydrocarbon could not be obtained by the usual reactions. One of the main proofs advanced by me for the constitution of tetraphenylmethane was that it furnished a tetranitro derivative which gave no colored salts with alcoholic potash, while most of the less phenylated methanes do respond to this test. To prove whether

1 Hemilian: Ber.d. chem. Ges., 7, 1207.

2 Ber. d. chem. Ges.. 30, 2043 ; This Journa1, $20,773$. 